\title{
A Longitudinal Study on the Trajectories and Influencing Factors of Elementary School Adjustment: Applying Growth Mixture Model and Latent Class Analysis
}

\author{
Eun Ha Her ${ }^{1}$, Sang Lim Kim² \\ Doctoral Student, Department of Early Childhood Nature-Friendly Education, Incheon National University, Korea ${ }^{1}$ \\ Associate Professor, Department of Early Childhood Education, Incheon National University, Korea ${ }^{2}$ \\ 초등학교 1-3학년 아동의 학교적응 변화의 유형 및 영향요인에 대한 종단연구: \\ 성장혼합모형과 잠재계층분석을 활용하여 \\ 허은하 ${ }^{1}$, 김상림 ${ }^{2}$ \\ 인천대학교 유아·숲·자연교육학과 박사과정 ${ }^{1}$ 인천대학교 유아교육과 부교수 ${ }^{2}$
}

\begin{abstract}
Objectives: The purpose of the study was to not only classify the latent class according to the trajectory of changes in the school adjustment of elementary school children in Grades 1-3, but also analyze the factors affecting school adjustment.

Methods: Data from the Panel Study on Korean Children of the Korea Institute of Childcare and Education were analyzed from wave 7 (2014) to wave 10 (2017). The growth mixture model was applied to derive the latent class according to the trajectory of changes in the elementary school adjustment of children in Grades 1-3. A multiple logistic regression analysis was conducted to analyze whether school readiness, social competence, play interaction, play interference, and play interruption affected the latent class classification of school adjustment.

Results: First, the growth trajectory of the sub-factors of school adjustment revealed the latent groups of 2 to 3. Second, the potential groups of school adjustment of elementary students in Grades 1-3 were identified as follows: (1) adaptation-decreasing, (2) high adaptation-stable, (3) adaptation-increasing, and (4) low adaptation-stable. Third, the factors that had significant effects on the latent class types of school adjustment were school readiness, social competence, and play interference.

Conclusion: The results of the study revealed the growth trajectories of elementary school children's school adjustment, suggesting the importance of improving school readiness, social competence, and play competence, which affect school adjustment trajectories.
\end{abstract}

Keywords: school adjustment, school readiness, social competence, play interaction, play interference, play interruption, growth mixture model, Panel Study on Korean Children

\section{Introduction}

학교는 한 사회의 가치관을 전달하고 유지하기 위한 사회적 기관으로, 지식 습득과 함께 인성 함양을 목적으로 전인적인

Corresponding Author: Sang Lim Kim, Associate Professor, Department of Early Childhood Education, Incheon National University, 12, Get-peal-ro, Yeonsoo-gu, Incheon, South Korea

E-mail: slkim@inu.ac.kr
교육을 추구한다. 사회적 조직으로서의 학교는 다양한 활동과 인간관계를 경험하는 장이며, 학습자는 학교라는 환경에 적응 하면서 배움을 통해 사회의 일원으로 성장하게 된다. 유아기 를 거쳐 초등학교에 입학하면서 아동은 학교라는 맥락에 적응

(C)The Korean Association of Child Studies

This is an Open Access article distributed under the terms of the Creative Commons Attribution Non-Commercial License (http:// creativecommons.org/licenses/by-nc/4.0) which permits unrestricted noncommercial use, distribution, and reproduction in any medium, provided the original work is properly cited. 
하는 새로운 발달과제에 직면하게 된다. 이는 도전적인 과제 이며, 초등학교에 대한 원활한 적응은 이후 시기의 성공적인 발달로 이어져 궁극적으로 효과적인 학교교육 목표를 달성하 는데 기여한다(Oh \& Lee, 2019; Richman, Bowen, \& Woolley, 2004). Ladd, Kochenderfer와 Coleman (1996)은 아동이 학교환 경 안에서 학교생활에 관심을 가지고 적극적으로 참여하며 전 반적인 학교생활 영역에서 성공을 이루는 정도로 학교적응을 정의하였다. 이와 같은 의미에서 학교적응은 아동이 학교라는 맥락 속에서 정해진 규칙을 준수하고 주어지는 수업과 활동에 적극적으로 참여하며 성공적으로 학교생활을 영위하는 것으 로 볼 수 있다.

초등학교의 학교적응을 고찰한 다수의 선행연구들은 주로 횡단적인 연구방법을 사용해 왔으나(S. A. Lee \& Lim, 2019; Yi \& Jun, 2019), 소수의 선행연구에서 종단적 연구방법을 통해 학교적응의 변화궤적이 연구된 바 있다(Jeon, Kim, \& Hong, 2020; E.-J. Kim, 2009). 예를 들어, 초등학교 저학년인 1학년 3 학년을 대상으로 한 종단연구에서 학년이 증가할수록 학교 적응 또한 점차 증가하는 것으로 밝혀졌으며(E.-J. Kim, 2009), 초등학교 고학년인 4학년 6학년을 대상으로 한 연구를 통해 학년이 증가할수록 학교적응이 점차 감소하는 것으로 나타난 바 있다(J. Lee, Kang, Lee, \& Yi, 2015). 나아가 일부 선행연구에 서는 초등학교 고학년과 중학생을 연구대상으로 포함하여 종 단연구를 실시했다. 그 결과, 초등학교 4학년에서 중학교 시기 까지 학년이 올라갈수록 학교적응이 점차 감소하는 것으로 나 타났다(S. Choi \& Yoo, 2019; E. Lee, Lee, \& Hong, 2016; Y. Lee \& Chung, 2016; Nam \& Kim, 2017).

한편, 앞서 살펴본 학교적응에 대한 종단적 분석 연구는 대 부분 잠재 성장 모형(Latent Growth Model [LGM])을 사용하 고 있다. 잠재 성장 모형은 다양한 시점, 즉 시간에 따른 변화 를 검증할 수 있다는 장점이 있으나, 모든 아동의 학교적응 수 준이 같은 추이로 변화한다고 볼 수 없으므로, 개별 아동이 적 응에 있어서 어떠한 변화궤적으로 서로 다르게 변화하는지 를 밝히는 데에는 한계를 가지고 있다(Hedeker, 2004). 이와 같 은 한계점을 보완하는 분석 방법으로 성장혼합모형(Growth Mixture Model [GMM])을 활용할 수 있으나, 이를 활용하여 초 등학생의 학교적응을 분석한 선행연구는 소수에 불과한 실정 이다. 해당하는 선행연구 결과를 살펴보면, Jeon 등(2020)은 저 학년 아동의 학교적응 변화 유형을 분석하여 감소 집단, 증가 집단, 저수준유지 집단, 고수준유지 집단의 4 개 유형으로 제안 하였다. 또한, $\mathrm{Nam}$ 과 $\mathrm{Kim}$ (2017)은 초등학교 4학년 중학교 2 학년 아동의 학교적응 변화궤적을 성장혼합모형을 통해 분
석하여 고적응 유지군, 저적응 유지군, 점진적 적응증가군, 점 진적 적응감소군, 점진적 미세 감소군의 5 개 유형으로 제안했 다. 이에 본 연구에서는 학교적응의 하위요인별 성장혼합모형 분석을 통하여 초등학교 1-3학년까지의 학교적응 변화궤적을 종단적으로 분석하고자 한다. 나아가 학교적응에는 학교생활 적응, 학업수행적응, 또래적응, 교사적응의 네 가지 하위요인 이 포함되므로, 초등학교 1-3학년의 학교적응 변화궤적을 하 위요인별로 고찰하겠다.

한편, 아동의 학교적응에 영향을 미치는 다양한 변인들에 대한 선행연구가 실행되어왔으며, 본 연구에서는 학교준비 도, 사회적 유능감, 놀이상호작용, 놀이방해, 놀이단절에 초 점을 두어 영향력을 검증하고자 한다. United States, National Education Goals Panel과 Goal 1 Technical Planning Group (1995) 은 학교준비도에 대하여 취학 전 유아가 초등학교에 진학 후 적극적이고도 긍정적인 학교생활을 하기 위하여 준비된 상태 로 정의한 바 있다. 즉, 학교준비도는 인지발달과 함께 학습에 대한 올바른 태도와 정서적 그리고 사회적 능력의 영역을 포 괄적으로 포함하는 개념이다(Her \& Kim, 2020). 취학 전 유아 가 유아교육기관을 졸업하고 초등학교에 입학하는 것은 아동 기의 매우 중요한 사건으로 간주되며, 이러한 맥락에서 유아 의 학교준비도는 초반부 학교생활에 잘 적응하기 위해 요구 되는 의미 있는 변인이다(Her \& Kim, 2020; S. A. Lee \& Lim, 2019). 즉, 유아의 높은 학교준비도는 성공적인 학교생활 수행 을 지원하여 안정된 전이(Ramey \& Ramey, 2004)를 가능하도 록 돕는다. 구체적으로 취학 전 유아의 학교준비도에 따라 초 등학교에서의 적응수준이 달라진다는 선행연구 결과가 있다 (An, 2014). 이와 함께 일부 선행연구에서는 유아의 학교준비 도가 이후의 발달 및 학업성취 등에 장기적으로도 긍정적인 영향을 미치는 것으로 보고하고 있다(H. S. Kim, 2013; J. Kim, 2019; Rouse \& Fantuzzo, 2009).

초등학교 저학년의 학교적응에 영향을 미치는 또 다른 변 인으로 사회적 유능감을 들 수 있다. 사회적 유능감이란 타인 과의 관계를 원만하게 유지하기 위한 사회적인 기술의 정도를 의미한다. 또한, 한 개인이 속한 사회에서 공유하는 규범을 이 해하며, 나아가 자신의 정서와 행동을 사회적인 상황에 적합 하도록 조절할 수 있도록 인지적, 정서적, 그리고 행동적인 자 원을 통합하는 능력을 뜻한다(Raver \& Zigler, 1997). 초등학교 아동의 학교적응과 관련하여 사회적 유능감을 고찰한 선행연 구 결과를 살펴보면, 높은 사회적 유능감을 가진 아동의 경우 초등학교 적응에 있어서도 우수한 것으로 보고된다(Kang \& Lee, 2001; S. Lee \& Oh, 2019; S. A. Lee \& Lim, 2019). 사회적 
유능감이 높은 아동들이 학교에서 이루어지는 다양한 활동에 적극적으로 참여하며 교사의 가르침에도 긍정적으로 잘 따르 는 경향인 것으로 나타났다(Gresham \& Elliott, 1990). 초등학 교 적응과 학업성취도 간의 관계에 있어서 유아의 사회적 유 능감이 매개효과를 가지는 것으로도 보고된 바 있으며(Yeom \& Moon, 2008), 유아기의 사회적 유능감이 초등학교 적응에 미치는 종단적 연구 결과(K.-H. Lee, 2018)를 통해 사회적 유능 감의 장기적인 영향력이 검증되었다. 이같이 사회적 유능감과 학교적응의 관계에 관한 일관된 선행연구 결과를 토대로 사회 적 유능감은 초등학교 아동의 학교적응에 직접적인 영향을 미 치는 예측변인임을 알 수 있다.

이와 함께 초등학교 아동의 학교적응과 관련된 변인으로 다수의 선행연구에서 유아기 또래 놀이 상호작용의 영향력을 고찰한 바 있다. 유아기의 또래 놀이 상호작용은 놀이상호작 용과 놀이방해 및 놀이단절의 세 가지 유형을 포함하고 있으 며, 이들 하위요인에 대한 선행연구 결과에 근거하여 학교적 응과의 관련성을 유추할 수 있다. 먼저 놀이상호작용이란 또 래와의 놀이를 순조롭게 이어가고 또래들을 도와주거나 격 려하는 등 친사회적인 행동을 하는 것을 의미한다(Park, Ma, $\&$ Chon, 2004). 놀이상호작용과 초등학교 아동의 학교적응 과 관련된 선행연구들을 살펴보면, 유아기의 활발한 놀이상호 작용은 초등학교 진학 후 학교적응에 긍정적인 영향을 미치 는 것으로 나타났다(E. J. Choi \& Kim, 2020). Ladd (2005)는 또 래와의 놀이상호작용을 성공적으로 수행하는 유아는 초등학 교 진학 후 학교적응에 있어서도 우수함을 보고했다. 이와 함 께 또래와 놀이 시 긍정적 상호작용을 많이 보이는 유아의 경 우 초등학교 진학 후 학업성취 또한 높게 나타났다(Coolahan, Fantuzzo, Mendez, \& McDermott, 2000). 이와 같은 선행 연구 결과를 통해 유아의 긍정적인 놀이상호작용이 학교적응에 영 향을 미침을 알 수 있다.

또래 놀이 상호작용의 또 다른 하위요인으로 놀이방해와 놀이단절이 있다. 이들 하위요인은 또래 놀이와 관련된 부정 적인 상호작용으로, 긍정적 측면의 놀이상호작용과 구분된다. 먼저 놀이방해는 공격적 행동과 자아통제의 결여와 관련된 또 래 놀이 상호작용의 부정적 차원을 의미한다(Park et al., 2004). 즉, 놀이방해는 또래와 놀이를 위한 상호작용을 지속하기보다 는 갈등을 유발하는 부정적인 행동 특성을 포함하는 것을 의 미하는데, 유아기의 놀이방해는 초등학교 아동의 학교적응과 관련된 것으로 보고된다. 예를 들어, 유아의 놀이방해 수준은 초등학생의 학업수행 능력이나 교사 또는 또래와의 관계 형성 과 같은 학교적응 정도와 관련된 것으로 나타났다(Jung \& Chi,
2006). 다음으로 놀이단절은 또래와 상호작용을 시작하기 어 려워하거나 상호작용을 시작하더라도 또래와의 놀이 상호작 용을 연속하여 이어나가지 못하고 놀이를 중단하게 되는 것을 의미한다(H. Y. Choi \& Shin, 2008). 관련 선행연구(Fantuzzo, Coolahan, Mendez, McDermott, \& Sutton-Smith, 1998) 결과에 의하면 놀이단절을 많이 보이는 유아의 경우, 심적으로 위축 되어 놀이를 시작하기 어려워하거나 놀이를 시작하더라도 활 발한 상호작용으로 이어가지 못하게 되어, 또래로부터 무시 당하거나 거부되는 상황에 놓여 궁극적으로 학교생활에 적응 하는 데 어려움을 겪는 것으로 나타난다. 놀이단절은 나아가 외로움이나 우울 또는 사회적 불안과 같은 부정적인 심리적 요인을 동반하여 학교적응에 부정적인 영향을 미치는 것으로 도 밝혀진 바 있다(Y.-J. Hong, An, Lee, \& Choi, 2018). 요약하 면, 유아의 또래 놀이 상호작용 중 놀이상호작용은 학교적응 에 정적인 영향을 주는 반면, 놀이방해와 놀이단절은 부적인 영향을 주는 것으로 추론할 수 있다. 따라서 학교적응에 미치 는 영향을 고찰함에 있어 놀이상호작용과 놀이방해 및 놀이단 절의 영향력을 각각 검증하고자 한다.

이상에서와 같이 관련 선행연구 결과를 통해 초등학교 학 교적응과 관련된 유아기의 변인으로 학교준비도와 사회적 유 능감, 그리고 또래 놀이 상호작용과 관련된 하위요인인 놀이 상호작용, 놀이방해, 놀이단절이 있음을 알 수 있다. 이에 본 연구에서는 성장혼합모형 분석을 통하여 초등학교 1학년 3 학년의 학교적응의 변화양상에 따른 잠재계층을 구분하고, 이 에 관련된 변인들로 학교준비도, 사회적 유능감, 놀이상호작 용, 놀이방해, 놀이단절을 선정하여 영향력을 검증하고자 한 다. 이와 같은 본 연구의 연구목적을 수행하기 위해 다음의 연 구문제를 구체적으로 설정하였다.

\section{연구문제 1}

초등학교 1-3학년 아동의 학교적응 하위요인별 변화궤적은 어떠한 유형으로 구분되는가?

\section{연구문제 2}

초등학교 1-3학년 아동의 학교적응 변화궤적은 어떠한 유형 으로 구분되는가?

\section{연구문제 3}

초등학교 1-3학년 아동의 학교적응 변화궤적에 미치는 유아 기 학교준비도, 사회적 유능감, 놀이상호작용, 놀이방해, 놀이 단절의 영향은 어떠한가? 


\section{Methods}

\section{연구대상}

본 연구에서는 육아정책연구소(Korea Institute of Child Care and Education [KICCE])의 한국아동패널(Panel Study on Korean Children [PSKC]) 자료 중 연구대상이 만 6세가 되는 7 차년도(2014년) 자료부터 만 9세가 되는 10차년도(2017년) 자 료를 사용했다(PSKC, 2018). 7차년도(2014년)에서 10차년도 (2017년) 각각의 아동의 조사 참여 대상은 각각 1,203 명, 1,031 명, 930 명, 633 명이며 평균 월령은 75 개월, 87 개월, 99 개월, 112 개월이었다.

\section{연구도구}

아동의 학교적응 변화궤적을 확인하기 위해서는 최소 세 시점 이상의 종단자료가 필요하다. 이에 본 연구는 초등학령기인 8 차년도(2015년) 조사부터 10차년도(2017년) 조사 중 응답을 한 번이라도 한 1,440 명의 세 시점의 자료를 활용하였으며, 영 향요인을 위한 자료로 같은 대상의 학령기 이전 7차년도(2014 년) 조사 데이터를 활용하였다. 초등학교 1-3학년 아동의 학교 적응의 잠재계층에 영향을 주는 결정 요인으로 학교준비도, 사회적 유능감, 또래 놀이 상호작용의 하위요인인 놀이상호작 용, 놀이단절, 놀이방해를 활용하였다. 초등학령기 이전의 7차 년도(2014년) 자료에서 변수를 설정하였다.

\section{학교적응}

연구대상의 학교적응을 알아보기 위해 Chi와 Jung (2006)이 개발한 학교적응 척도를 사용했다(PSKC, 2018). 본 척도는 총 35 문항, 4 가지 하위요인(학교생활적응, 학업수행적응, 또래 적응, 교사적응)으로 구성된다. 각 하위요인에 대해 살펴보면, 학교생활적응(school life adjustment, 11 문항)은 규칙 및 질서 에 대한 적응, 교사의 요구나 지시에 대한 적응을 의미한다. 학 업수행적응(academic performance adjustment, 11 문항)은 활동 의 의욕성, 수업시간의 활동과 적극적인 자세를 의미한다. 또 래적응(peer adjustment, 8 문항)은 친구들과의 갈등 해결의 형 태, 또래에 대한 친사회적 행동을 의미한다. 교사적응(teacher adjustment, 5 문항)은 선생님과 자유롭게 이야기하고 선생님 께 도움을 잘 청하는 것을 의미한다. 연구대상 아동의 담임교
사가 각 문항을 읽고 전혀 그렇지 않다(1점)부터 매우 그렇다 (5점)로 응답하는 5점 Likert식 척도이다. 본 연구에서는 8차년 도(2015년) 10차년도(2017년)의 학교적응의 하위요인 점수 와 총점을 사용하였으며 점수가 높을수록 아동의 학교적응이 높음을 의미한다. 학교적응의 문항신뢰도 Cronbach's $\alpha$ 는 8 차 년도는 학교생활적응 .96 , 학업수행적응 .94 , 또래적응 .94 , 교 사적응 .84, 전체 .97이며, 9차년도는 학교생활적응 .96, 학업 수행적응 . 94 , 또래적응 .93 , 교사적응 .81, 전체 .97로 나타났 고, 10 차년도는 학교생활적응 .95 , 학업수행적응 .94, 또래적 응 .94, 교사적응 .82 , 전체 .97이었다.

\section{학교준비도}

취학 전 유아의 학교준비도를 알아보기 위해 Murphey와 Burns (2002)의 학교준비도(School Readiness) 척도를 사용했다 (PSKC, 2018). 본 척도는 총 22문항, 4 가지 하위요인(사회 정 서 발달, 학습에 대한 태도, 의사소통, 인지 발달 및 일반적 지 식)으로 구성되어 있다. 각 하위요인에 대해 살펴보면, 사회 정서 발달(social and emotional development, 6 문항)은 다른 아 이들과 놀 수 있고, 학습에 대한 접근을 의미하며, 학습에 대 한 태도(approach to learning, 8문항)는 열정, 호기심, 끈기와 같은 성향을 의미한다. 의사소통(communication, 3 문항)은 수 용 및 표현을 의미하며, 인지 발달 및 일반적 지식(cognitive development and general knowledge, 5문항)은 학습자료의 내용 과 목표를 이해하는 것을 의미한다. 육아지원기관의 담임교사 가 각 문항을 읽고 전혀 그렇지 않다(1점)부터 매우 그렇다(4 점)로 응답하는 4점 Likert식 척도이다. 본 연구에서는 총점을 사용하였으며 점수가 높을수록 취학 전 유아의 학교준비도가 높음을 의미한다. 학교준비도의 문항신뢰도 Cronbach's $\alpha$ 는 .93 이었다.

\section{사회적 유능감}

유아의 사회적 유능감을 알아보기 위해 Gresham과 Elliott (1990)가 개발한 Social Skills Rating System (SSRS)를 Suh (2004) 가 번역하고 타당화한 한국판 취학 전 아동용 사회적 기술 척 도(K-SSRS)를 사용했다(PSKC, 2018). 본 척도는 총 21문항, 3 가지 하위요인(주장성, 협력성, 자기통제)으로 구성되어 있다. 각 하위요인에 대해 살펴보면 주장성(assertiveness, 5문항)은 놀이를 할 때 다른 아이에게도 같이 하자고 말하는 것을 의미 하며, 협력성(cooperation, 9문항)은 교사의 지시에 잘 따르기, 
친구들과 단체 활동에 잘 참여하는 것을 의미한다. 자기통제 (self-control, 7문항)는 친구에게 놀림을 당하는 경우 적절하게 대응하기, 자신의 의견 양보하기와 같은 것을 의미한다. 육아 지원기관의 담임교사가 각 문항을 읽고 전혀 아니다(1점)부터 매우 자주 그렇다(3점)로 응답하는 3점 Likert식 척도이다. 본 연구에서는 총점을 사용하였으며 점수가 높을수록 유아의 사 회적 유능감이 높음을 의미한다. 사회적 유능감의 문항신뢰도 Cronbach's $\alpha$ 는 .92이었다.

또래 놀이 상호작용(놀이상호작용, 놀이방해, 놀이단절)

또래 놀이 상호작용을 알아보기 위해 Fantuzzo 등(1998)이 개 발하고 H. Y. Choi와 Shin (2008)이 번역 및 타당화한 척도를 사용했다(PSKC, 2018). 본 척도는 총 30 문항, 3 가지 하위요인 (놀이상호작용, 놀이방해, 놀이단절)으로 구성되어 있다. 각 하위요인에 대해 살펴보면, 놀이상호작용(play interaction, 9문 항)은 놀이를 자연스럽게 이어가는 것을 의미하며, 놀이방해 (play disruption, 13문항)는 공격적이고 부정적인 정서 표현 등 을 의미한다. 놀이단절(play disconnection, 8 문항)은 위축되거 나 친구에게 무시당하거나 거부당하는 것을 의미한다. 육아지 원기관의 담임교사가 각 문항을 읽고 전혀 그렇지 않다(1점) 부터 항상 그렇다(4점)로 응답하는 4점 Likert식 척도이다. 본 연구에서는 종속변인인 학교적응에 미치는 영향을 검증함에 있어 하위요인별 점수를 사용하였으며, 점수가 높을수록 놀 이상호작용, 놀이방해, 놀이단절이 높음을 의미한다. 하위요 인의 문항신뢰도 Cronbach's $\alpha$ 는 놀이상호작용 .81 , 놀이방해 .88 , 놀이단절 .89 이었다.

\section{자료분석}

본 연구에서 사용한 자료는 SPSS 22.0 (IBM Co., Armonk, NY) 과 AMOS 21.0 (IBM Co., Armonk, NY) 및 Mplus 7.4 (Muthén $\&$ Muthén, Los Angeles, CA) 프로그램을 활용하여 분석을 실 시하였다. 연구대상자들의 인구통계학적 특성을 알아보기 위 한 빈도분석과 변인별 평균과 표준편차 등의 기초통계를 실 시하고, 측정도구의 신뢰도를 알아보기 위하여 신뢰도 계수 (Cronbach's $\alpha$ )를 산출했다. 본 연구에서는 연구문제별로 서 로 다른 분석방법을 사용하였다. 첫째, 연구문제 1 인 초등학 교 1-3학년 아동의 학교적응 하위요인별 변화궤적 유형을 알 아보기 위해 성장혼합모형(GMM)을 활용하여 3차년도의 데
이터에 대해서 학교적응 하위요인별 궤적을 추정하고 몇 개의 집단으로 구분되는지 파악하였다. 둘째, 연구문제 2인 초등학 교 1-3학년 아동의 학교적응 변화궤적은 어떠한 유형으로 구 분되는지 도출하기 위해 잠재 성장 모형(LGM) 분석을 실시하 여 무변화모형과 선형모형 간 모형적합도를 비교 후, 전체 집 단 내 서로 다른 변화양상을 보이는 하위 잠재 계층 성장 모형 을 추정하기 위하여 성장혼합모형(GMM) 분석을 실시했다. 학교적응 변화궤적에 몇 개의 하위계층이 존재하는지 잠재계 층 수 결정하기 위해 통계적 적합도와 해석 가능성을 함께 고 려하였다(Wickrama, Lee, O’Neal, \& Lorenz, 2016). 적합도는 정보준거지수인 AIC (Akaike Information Criteria), BIC (Baysian Information Criteria), SABIC (Sample-size Adjusted BIC), 계층 분류의 질을 평가하는 Entropy 지수, 경쟁모형과 적합의 통 계검증을 나타내는 LMR (Lo-Mendell-Rubin), BLRT (LRT Bootstrap) 검증 등을 근거로 최적의 잠재집단 수를 결정하였 다. 셋째, 연구문제 3을 검증하기 위해 성장혼합모형 (GMM) 분석에서 도출한 잠재계층에 영향을 미치는 영향요인을 다항 로지스틱 회귀분석(multiple logistic regression)을 실시하여 어 떠한 영향요인에 따라서 집단 간 차이가 나타나는지 확인하였 다. 본 연구에서는 선행연구들을 통해 학교적응을 예측한다고 밝혀진 학교준비도, 사회적 유능감, 놀이상호작용, 놀이방해, 놀이단절을 선택하여 이들 예측변인을 활용한 조건 모형으 로 분석을 진행하였다. 하나의 잠재 계층 안에서도 개인차 분 산을 추정하고, 개인차에 대한 설명을 시도하는 이론적 전제 (Muthén, 2004) 하에 분석을 진행하였으며, 1 차 시기를 기준점 으로 분석을 실시하였다. 결측치 처리를 위해서 완전정보최대 우도법(Full Information Maximum Likelihood [FIML])을 이용 하였다. 최종연구모형은 Figure 1과 같다.

\section{Results}

\section{주요 변인의 기술통계}

본 연구에서 분석된 주요 변인의 평균값 $(M)$ 및 표준편차 $(S D)$ 를 통하여 데이터의 특성을 보다 구체적으로 살펴보았으며, 왜도 및 첨도를 분석하여 자료 분포의 적절성을 확인했다. 평 균(표준편차)을 살펴보면, 유아의 학교준비도 $M=3.49$ ( $S D$ $=.41)$, 사회적 유능감 $M=2.53(S D=.36)$, 놀이상호작용 $M=$ $3.09(S D=.45)$, 놀이방해 $M=1.93(S D=.52)$, 놀이단절 $M=$ $1.64(S D=.59)$ 로 나타났다. 다음으로 학교적응 점수는 4 개 하 


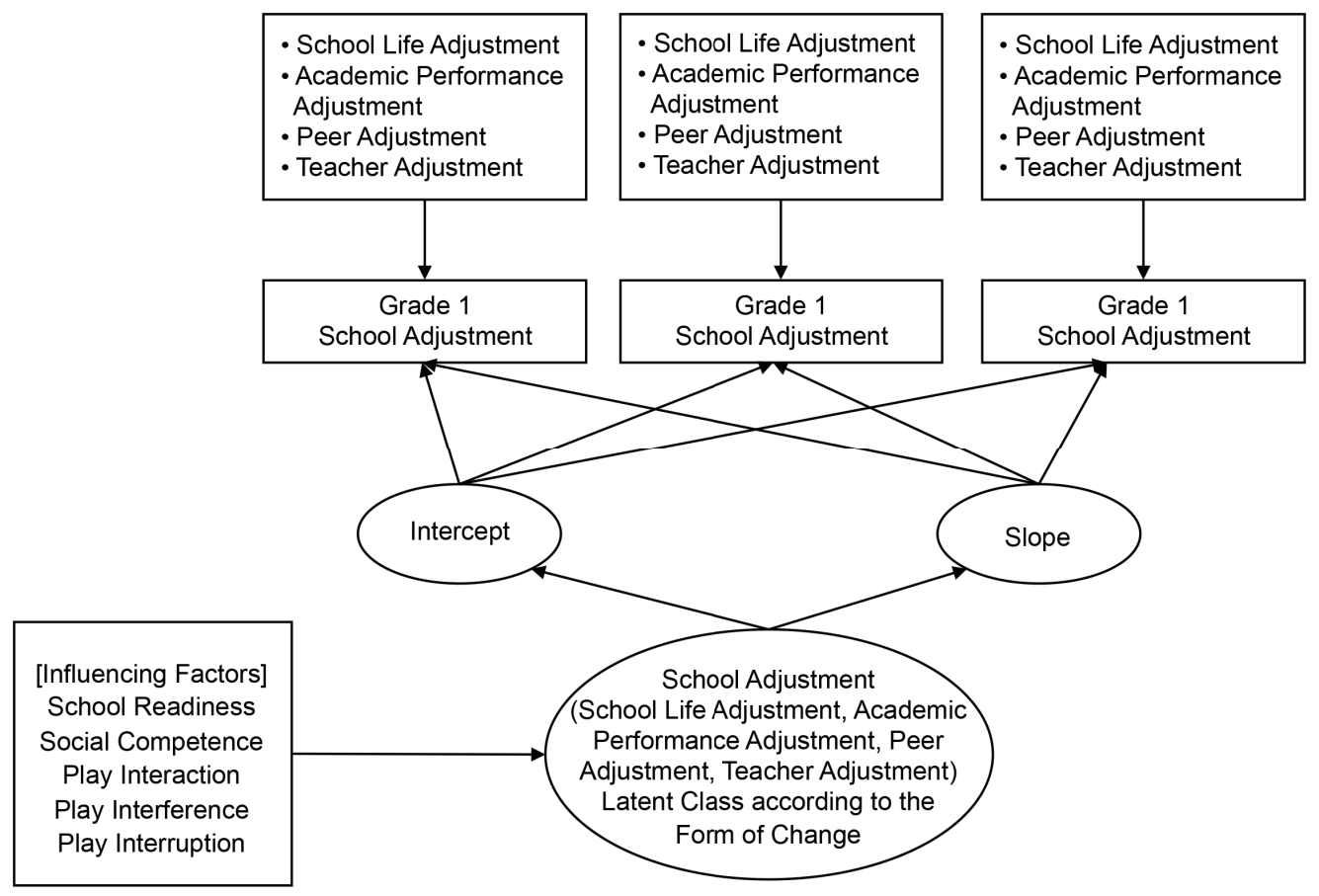

Figure 1. Final research model.

위요인에서 모두 학년이 올라가면서 증가하는 것으로 나타났 다. 구체적으로 살펴보면 8차년도 학교생활적응 $M=4.08$ ( $S D$ $=.94)$, 학업수행적응 $M=3.83(S D=.86)$, 또래적응 $M=3.95$ $(S D=.81)$, 교사적응 $M=4.01(S D=.76)$ 로 나타났으며, 9차년 도 학교생활적응 $M=4.07(S D=.89)$, 학업수행적응 $M=3.88$ $(S D=.82)$, 또래적응 $M=3.92(S D=.78)$, 교사적응 $M=3.99$ $(S D=.70)$ 로 나타났다. 또한, 10 차년도 학교생활적응 $M=4.23$ $(S D=.83)$, 학업수행적응 $M=3.99(S D=.80)$, 또래적응 $M=$ $4.09(S D=.79)$, 교사적응 $M=4.06(S D=.74)$ 이었다. 특히 학 교적응의 하위요인인 학교생활적응, 학업수행적응, 또래적응, 교사적응은 3학년 평균 점수가 4점을 상회하는 수준으로 높 아졌다. 또한, 분석에 포함된 변인들 모두 왜도(-1.26 1.15)는 절대 값 3 미만, 첨도(-.12 1.22)는 절대 값 10 미만으로 나타 나 정상분포 가정을 충족하는 것을 확인하였다.

\section{학교적응의 하위요인별 변화궤적 유형}

\section{초등학교 1-3학년 아동의 학교적응의 하위요인별} 변화궤적의 잠재계층 수 결정

초등학교 1-3학년 아동의 학교적응의 하위요인별 변화궤적 유형을 확인하기 위해 성장혼합모형(GMM)분석을 실시하
고 그 결과를 Table 1 에 제시하였다. 우선 최적의 잠재계층 수 를 확인하기 1 개부터 5 개까지 증가시켜가며 잠재계층의 적합 도를 비교하였다. 최종적인 잠재계층의 개수는 통계적인 적 합성과 해석가능성을 함께 고려하여 결정하였다. 정보준거지 수(AIC, BIC, SABIC)는 값이 낮을수록 모형이 적합함을 의미 하며, Entropy 지수는 하나의 잠재계층에 속할 확률이 1 에 가 깝고 다른 잠재계층에 속할 확률이 0 에 가까울수록 값이 증가 한다. 범위는 0-1 사이이며, 대략 .8 이상이면 좋은 분류라고 할 수 있다(Muthén, 2004). LMR은 이전 모형(집단 수 k-1개) 과 현재모형(집단 수 $\mathrm{k}$ 개)을 비교하여 $p$ 값이 유의하지 않을 경 우 이전 모형이 현재 모형의 적합도보다 더 우수함을 의미한 다(Lo, Mendell, \& Rubin, 2001). 첫 번째, 학교생활적응에 대 한 모형 적합도의 경우 $\mathrm{AIC}$ 와 $\mathrm{BIC}$ 값은 완만한 수준으로 감소 하는 경향을 보였으나, LMR 값은 2 개, 3 개, 4 개의 집단 모형 모두에서 유의한 것으로 나타났다. 집단별 사례 수는 2 개, 3 개 집단이 전체 표본 대비 각 집단 구성의 최소 비율인 $5 \%$ 이상 을 충족하였으며, 이에 2 개 집단과 3 개 집단을 중심으로 살펴 본 결과 해석 가능성을 고려하여, 2 개 집단 모형으로 선정하는 것이 적절한 것으로 판단하였다. 두 번째, 학업수행적응의 모 형 적합도의 경우 $\mathrm{AIC}$ 와 $\mathrm{BIC}$ 의 값은 완만한 수준으로 감소하 는 경향을 보였으나, LMR은 2개 집단 모형부터 유의하지 않 았다. 이에 2개 집단을 중심으로 살펴본 결과, 전체 표본 대비 
Table 1

Numbers and Names of the Groups by Sub-factors of School Adjustment

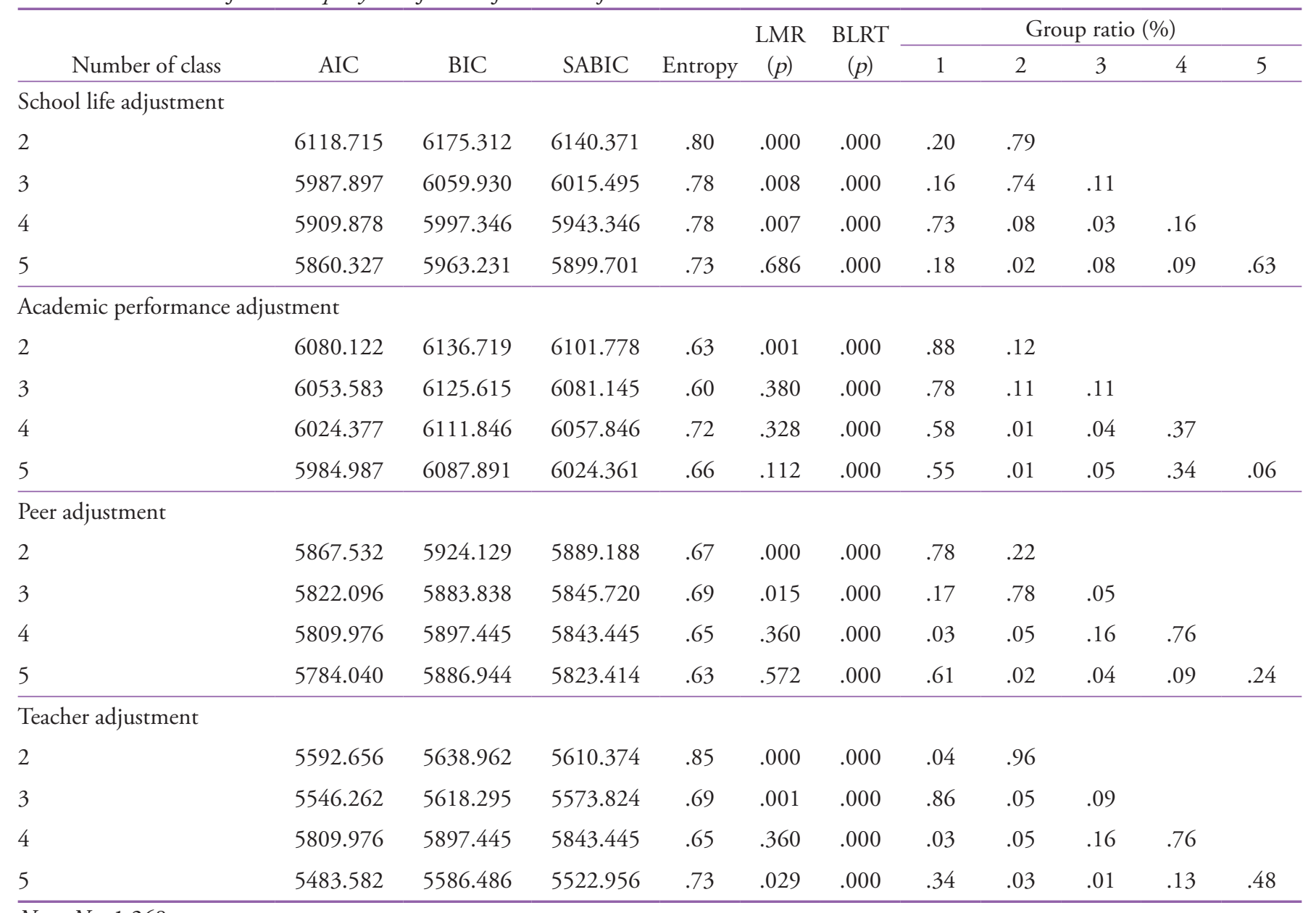

Note. $N=1,268$.

각 집단 구성의 최소 비율인 $5 \%$ 이상을 충족하고 있어 2 개 집 단 모형으로 선정하는 것이 적절한 것으로 판단하였다. 세 번 째, 또래적응의 모형 적합도의 경우 $\mathrm{AIC}$ 와 $\mathrm{BIC}$ 의 값은 완만한 수준으로 감소하는 경향을 보였으나, LMR은 2개, 3 개 집단이 모형에서 유의미한 것으로 나타났다.

이에 2 개 집단과 3 개 집단의 모형을 중심으로 적절성을 살 펴본 결과, Entropy 지수가 2개 집단이 3개 집단에 비해 조금 높게 나왔고, 해석 가능성을 고려하여, 3 개 집단 모형으로 선 정하는 것이 적절한 것으로 판단하였다. 네 번째, 교사적응의 모형 적합도의 경우 LMR은 2 개, 3 개 및 5 개 집단 모형에서 유 의미한 것으로 나타났다. 이에 2 개, 3 개 및 5 개 집단을 중심으 로 살펴본 결과, 3 개 집단이 전체 표본 대비 각 집단 구성의 최 소 비율인 $5 \%$ 이상을 충족하고 있어 3 개 집단 모형으로 선정 하는 것이 적절한 것으로 판단하였다.
초등학교 1-3학년 아동의 학교적응의 하위요인별 변화궤적의 유형별 특성

초등학교 1-3학년 아동의 학교적응 하위요인별의 유형별 특 성을 확인하기 위해 잠재계층별 사례수 및 평균을 산출하여 Table 2에 제시하였으며, Figure 2에서 이를 도표화하였다. 하 위요인별 잠재계층의 집단명은 1 학년과 2 학년 및 3 학년의 세 시점에 나타난 학교적응 수준의 변화 양상을 고려하여 명명 되었다. 즉, 세 시점 모두 높은 학교적응을 보이는 고적응 유지 집단, 점차 증가하는 양상의 적응 증가 집단과 점차 감소하는 양상의 적응 감소 집단, 낮아졌다가 다시 증가하는 적응 방향 변동 집단이 그것이다.

초등학교 1-3학년 아동의 학교적응 하위요인별 변화궤적 에 따른 특징은 다음과 같다. 첫째, 학교생활적응은 2 개 집단 으로 유형화되었는데 1학년부터 3학년까지 4점을 상회하는 
Table 2

Means and Frequencies of Groups by Sub-factors of School Adjustment

\begin{tabular}{|c|c|c|c|c|c|}
\hline & Group & $n(\%)$ & $\begin{array}{c}8 \mathrm{~T} \\
\text { /Grade } 1\end{array}$ & $\begin{array}{c}9 \mathrm{~T} \\
\text { /Grade } 2\end{array}$ & $\begin{array}{c}10 \mathrm{~T} \\
/ \text { Grade } 3\end{array}$ \\
\hline \multicolumn{6}{|c|}{ School life adjustment } \\
\hline Class 2 & Adaptation-increasing & $261(20.58)$ & $2.55(.61)$ & $3.05(.85)$ & $3.61(.92)$ \\
\hline \multicolumn{6}{|c|}{ Academic performance adjustment } \\
\hline Class 2 & Adaptation-fluctuating & $154(12.45)$ & $3.88(.86)$ & $3.84(.84)$ & $4.04(.75)$ \\
\hline \multicolumn{6}{|l|}{ Peer adjustment } \\
\hline Class 1 & High adaptation-stable & $989(77.98)$ & $3.94(.81)$ & $3.93(.78)$ & $4.08(.80)$ \\
\hline Class 2 & Adaptation-fluctuating & $61(4.81)$ & $4.10(.79)$ & $3.72(.81)$ & $4.02(.78)$ \\
\hline Class 2 & Adaptation-increasing & $64(5.04)$ & $3.81(.78)$ & $3.97(.70)$ & $3.97(.64)$ \\
\hline Class 3 & Adaptation-decreasing & $114(8.99)$ & $4.04(.76)$ & $4.03(.64)$ & $3.97(.76)$ \\
\hline
\end{tabular}

Note. $N=1,268$.

The result of the 5-point Likert scale.

고적응 유지(계층 1)가 $79.41 \%$ 로 다수를 차지하였다. 한편 계 층 2 는 초기에 보통 수준 보다 다소 낮은 수준이었으나, 점차 학교생활적응 수준이 3.61점까지 상승하여 적응 증가 집단으 로 명명하였다. 둘째, 학업수행적응은 2개 집단으로 유형화 되었는데 1학년부터 3학년까지 일정한 수준으로 높은 수준 을 유지하고 있는 고적응 유지(계층 1)가 $87.86 \%$ 로 다수를 차 지하였다. 계층 2 는 초등학교 2학년에 감소하다가 3학년에 다 시 증가하는 집단으로 적응 방향 변동 집단으로 명명하였다. 셋째, 또래적응은 시간이 경과함에 따라 3 개 집단으로 유형화 되었는데 1학년부터 3학년까지 일정한 수준으로 높은 수준을 유지하고 있는 고적응 유지(계층 1)가 $77.98 \%$ 로 다수를 차지 하였다. 꾸준히 증가하는 집단은 $17.19 \%$, 적응 방향의 변동을 보이는 집단은 $4.81 \%$ 를 보여주었으나, 3 집단 모두 3 학년에서 는 4점 이상으로 또래적응성을 보였다. 넷째, 세 개의 잠재계 층으로 구분된 교사적응의 경우, $2 / 3$ 에 해당하는 초등학생이 보통 수준을 상회하는 고적응 유지(계층 1)에 해당하였다. 한 편 완만한 증가를 보여주고 있는 적응 증가(계층 2)는 5.04\%, 적응 감소(계층 3 )는 $8.99 \%$ 로 학교적응 수준이 점차 증가하는 아동의 비율은 전체적으로 $91 \%$ 가량으로 매우 높았다. 초등학 교 1-3학년 아동의 학교적응 하위요인별 잠재계층별 변화궤 적은 Figure 2에 제시하였다.

\section{학교적응 변화궤적 유형}

\section{학교적응의 변화궤적 추정}

초등학생의 $1-3$ 학년의 학교적응을 3 개 시점에서 측정한 변 화궤적을 분석하기 위해 잠재성장모형(LGM)으로 무변화모 형과 선형모형을 설정하여 각각의 모형적합도를 비교하였다 (Table 3). 연구모형의 적합도를 평가하기 위해 표본 크기에 상 대적으로 민감한 $\chi^{2}$ 보다 표본크기에 덜 민감한 적합 지수들 (TLI, CFI, RMSEA)을 사용하여 평가하였다. 적합 지수를 활 용한 평가 기준으로는 선행연구(S. Hong, 2000)에 따라, TLI 와 CFI는 90 이상일 경우 양호한 것으로 해석했으며, RMSEA 는 .05 이하일 경우 좋음, .08 이하일 경우 양호, .10 이하일 경 우 보통으로 해석했다. 이에 따라 해석한 결과, 선형모형의 $\mathrm{CFI}=.97, \mathrm{TLI}=.84, \mathrm{RMSEA}=.05(95 \%, \mathrm{CI}=[.03 \sim .09])$ 로 모 형 적합도가 양호한 것으로 나타났다. Table 4에 제시된 학교 적응의 선형변화모형 추정치에 의하면 무변화모형은 학교적 응 수준이 일정할 것으로 가정하는 반면, 선형모형은 일정한 수준으로 낮아지거나 높아질 것으로 가정한다. 먼저 선형모형 의 초기치와 변화율의 예측평균이 모두 유의하게 나타났다. 즉, 초기치의 예측평균은 $3.99(p<.001)$ 이고, 변화율의 예측 

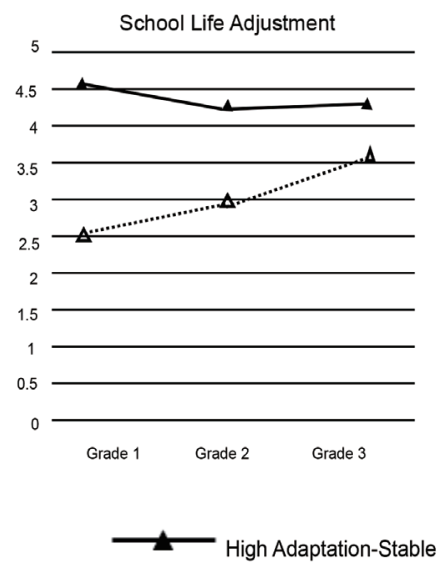
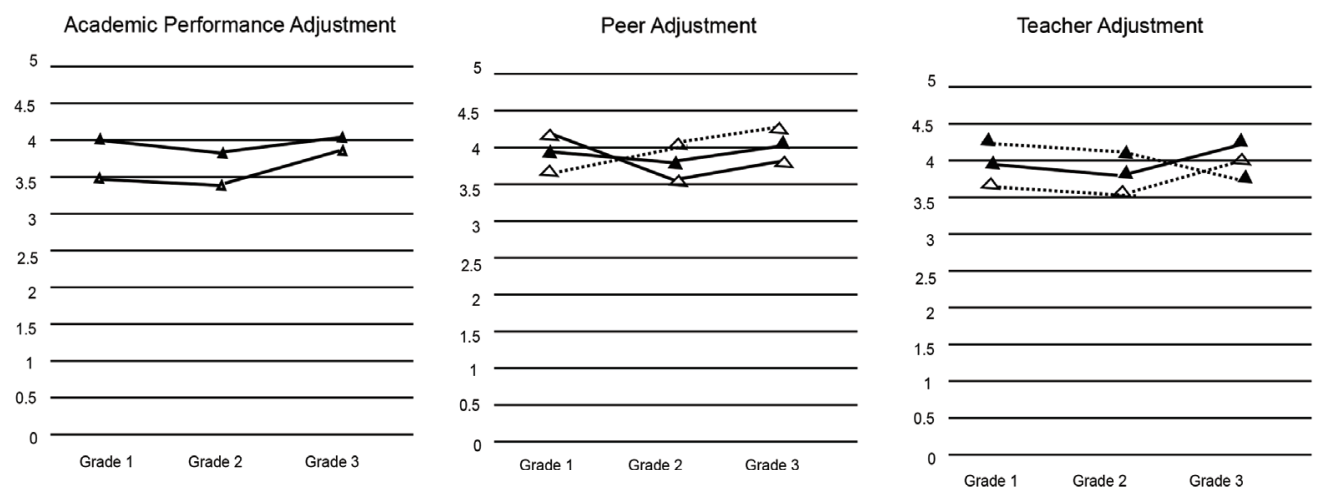

Figure 2. Group trends of elementary school children of Grades 1-3 by sub-factors of school adjustment.

The unit of the vertical axis is 5 -points.

Table 3

Latent Growth Model Fit of School Adjustment

\begin{tabular}{rlrcccc}
\hline & & & & & RMSEA \\
Variables & \multicolumn{1}{c}{ Type of change model } & \multicolumn{1}{c}{$\chi^{2}$} & $d f$ & CFI & TLI & $(95 \%$ CI $)$ \\
\hline School adjustment & No change model & 29.88 & 4 & .91 & .87 & $.05(.03 \sim .06)$ \\
& Linear change model & 8.45 & 1 & .97 & .84 & $.05(.03 \sim .09)$ \\
\hline
\end{tabular}

Table 4

Latent Growth Model Estimates of School Adjustment

\begin{tabular}{cccccc}
\hline Variables & \multicolumn{3}{c}{ Mean } & Variance & Covariance \\
\hline School adjustment & Intercept & Slope & Intercept & Slope & Intercept $\leftrightarrow$ Slope \\
& $3.99^{* * *}$ & $.06^{* * *}$ & $.27^{* * *}$ & .04 & -.05 \\
\hline
\end{tabular}

${ }^{* * *} p<.001$.

평균은 .06 ( $p$ < .001)으로 학교적응은 시간이 지남에 따라 점 차 증가하는 추세를 보였다. 이러한 결과는 기술통계의 추이 와도 일맥상통하는 것이다. 다음으로 초기치의 분산은 .27 ( $p$ $<.001)$ 로 유의했으나, 변화율의 분산은 .04 (ns)로 유의하지 않 게 나타나, 학교적응의 변화궤적에 있어서 개인차가 유의하지 않은 것을 알 수 있다. 또한, 초기치와 변화율 간 공분산은 -.05 $(n s)$ 로 유의하지 않은 것으로 밝혀졌다. 두 모형의 모형적합도 비교한 결과, 무변화모형 보다 선형모형이 본 연구자료를 더 잘 설명하는 것으로 나타났다.

초등학교 1-3학년 아동의 학교적응의 변화궤적의 잠재계층 수 결정

초등학교 1 학년 3 학년 아동의 학교적응의 변화궤적으로 분
석된 선형모형을 토대로, 전체 집단에서 서로 다른 변화를 보 이는 하위 잠재성장계층을 추정하기 위해 다음으로 성장혼 합모형 $(\mathrm{GMM})$ 을 사용하여 분석하였다. 아동의 학교적응 변 화궤적에 따른 잠재계층의 개수를 결정하기 위해 2 계층부터 5 계층까지 개수를 하나씩 증가시키면서 모형을 비교하였다 (Table 5). 정보준거지수, Entropy 지수, LMR 검정 결과를 기초 로 어떻게 변화하는지 살펴보았다. 5계층 모형이 가장 적합한 것으로 나타났지만, 잠재모형의 해석 가능성을 고려하면 5계 층 모형은 유의하지 않은 것으로 판단되었다. LMR은 2계층, 4 계층이 유의미한 것으로 나타났다. 이에 2 계층 모형과 4 계층 모형을 중심으로 적절성을 살펴본 결과, 통계적 수치와 기존 연구에서 산출된 집단의 개수에 근거하여 종합적으로 고려한 결과, 최적의 모형으로 4 계층 모형을 선정하고 이를 최종모형 으로 선정했다. 또한, 1 개의 잠재계층이 $3.71 \%$ 로 나타났지만 
Table 5

Fitness Index and Participant Information by Number of Strata in the Growth Mixture Model

\begin{tabular}{|c|c|c|c|c|c|}
\hline & \multicolumn{4}{|c|}{ Number of class } \\
\hline & & 2 & 3 & 4 & 5 \\
\hline AIC & & 5140.706 & 5097.009 & 5056.218 & 5023.835 \\
\hline BIC & & 5197.303 & 5158.752 & 5133.396 & 5116.449 \\
\hline SABIC & & 5162.362 & 5120.634 & 5085.749 & 5059.272 \\
\hline Entropy & & .626 & .661 & .642 & .695 \\
\hline $\operatorname{LMR}(p)$ & & .000 & .055 & .197 & .126 \\
\hline $\operatorname{BLRT}(p)$ & & .000 & .000 & .000 & .000 \\
\hline \multirow[t]{5}{*}{ Group ratio (\%) } & 1 & $1,049(82.73 \%)$ & $83(6.55 \%)$ & $210(16.56 \%)$ & $66(5.21 \%)$ \\
\hline & 2 & $219(17.27 \%)$ & $965(76.10 \%)$ & $833(65.69 \%)$ & $778(61.36 \%)$ \\
\hline & 3 & & $220(17.35 \%)$ & 178 (14.04\%) & $13(1.03 \%)$ \\
\hline & 4 & & & $47(3.71 \%)$ & $48(3.79 \%)$ \\
\hline & 5 & & & & $363(28.63 \%)$ \\
\hline
\end{tabular}

Table 6

Estimates for Trajectory Classes of School Adjustment

\begin{tabular}{llccccc}
\hline & & & \multicolumn{2}{c}{ Intercept } & \multicolumn{2}{c}{ Slope } \\
\cline { 4 - 7 } & Group & $n(\%)$ & $M$ & $S E$ & $M$ & $S E$ \\
\hline Class 1 & Adaptation-decreasing & $210(16.56 \%)$ & $3.84^{* * *}$ & .19 & -.29 & .18 \\
Class 2 & High adaptation-stable & $833(65.69 \%)$ & $4.30^{* * *}$ & .03 & $.06^{*}$ & .03 \\
Class 3 & Adaptation-increasing & $178(14.04 \%)$ & $3.09^{* * *}$ & .17 & $.50^{* *}$ & .17 \\
Class 4 & Low adaptation-stable & $47(3.71 \%)$ & $2.74^{* * *}$ & .19 & -.10 & .13 \\
\hline
\end{tabular}

${ }^{*} p<.05 .{ }^{* *} p<.01 .{ }^{* * *} p<.001$.

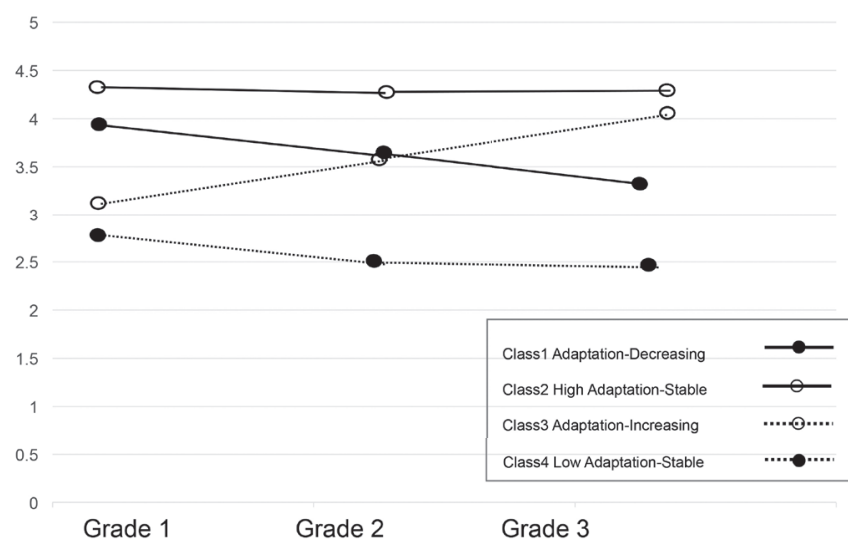

Figure 3. The structure of the potential classes according to the changes in school adjustment.

$5 \%$ 미만이라도 $1 \%$ 이상이면 의미 있는 잠재계층으로 수용할 수 있다는 연구(Hill, Degnan, Calkins, \& Keane, 2006)에 기반 하여 4계층 모형을 최종 선정하였다.
초등학교 1-3학년 아동의 학교적응 변화궤적 유형별 특성

초등학교 1-3학년 아동의 학교적응 변화궤적의 4 가지 유형별 특성을 확인하기 위해 잠재계층별 잠재계수 모수추정치인 초 기치와 변화율의 평균 및 표준오차를 산출하여 Table 6에 제시 하였다. 초등학교 1학년 3학년 아동의 학교적응 변화궤적에 따른 유형별 특징을 살펴보면 다음과 같다. 첫째, 계층 1 은 전 체의 210 명(16.56\%)을 차지하며, 초기에는 약 3.84로 높은 수 준의 학교적응도를 보이지만 이후 유의하게 감소하는 형태 를 보여 적응 감소 집단으로 명명하였다. 둘째, 계층 2 는 833 명(65.69\%)으로 가장 높은 비율을 차지하며, 1 학년 3 학년까 지 높은 수준으로 일정하게 유지하는 집단 특성을 고려하여 고적응 유지 집단으로 명명하였다. 셋째, 계층 3 은 초등학교 1-3학년까지 점차적으로 증가하는 추세를 보이며 전체 178 명 (14.04\%)을 차지하며 적응 증가 집단으로 명명하였다. 넷째, 계층 4 는 초등학교 1-3학년까지 일정하게 초기치의 가장 낮은 
Table 7

Predictors of School Adjustment Type

\begin{tabular}{|c|c|c|c|c|c|c|c|c|c|}
\hline \multirow{2}{*}{$\begin{array}{l}\text { Reference group } \\
\text { Comparative } \\
\text { group }\end{array}$} & \multicolumn{9}{|c|}{ Class 1: Adaptation-decreasing } \\
\hline & \multicolumn{3}{|c|}{$\begin{array}{c}\text { Class } 2 \\
\text { High adaptation-stable }\end{array}$} & \multicolumn{3}{|c|}{$\begin{array}{c}\text { Class } 3 \\
\text { Adaptation-increasing }\end{array}$} & \multicolumn{3}{|c|}{$\begin{array}{c}\text { Class } 4 \\
\text { Low adaptation-stable }\end{array}$} \\
\hline School readiness & 1.83 & .73 & $2.16^{*}$ & 1.63 & .88 & $2.20^{*}$ & -1.39 & 1.43 & .25 \\
\hline Social competence & 1.55 & .80 & $4.71^{*}$ & 1.67 & .97 & $5.33^{*}$ & 1.68 & 1.63 & 5.34 \\
\hline Play interference & .69 & .50 & 1.99 & .32 & .58 & 1.37 & 1.40 & .85 & $4.05^{*}$ \\
\hline Play interruption & -.57 & .43 & .57 & -.23 & .53 & .79 & -1.43 & .99 & .24 \\
\hline
\end{tabular}

\begin{tabular}{|c|c|c|c|c|c|c|c|c|c|}
\hline \multirow{2}{*}{$\begin{array}{l}\text { Reference group } \\
\text { Comparative } \\
\text { group }\end{array}$} & \multicolumn{6}{|c|}{ Class 2: High adaptation-stable } & \multirow{2}{*}{\multicolumn{3}{|c|}{$\begin{array}{c}\text { Class 3: Adaptation-increasing } \\
\text { Class } 4 \\
\text { Low adaptation-stable }\end{array}$}} \\
\hline & \multicolumn{3}{|c|}{$\begin{array}{c}\text { Class } 3 \\
\text { Adaptation-increasing }\end{array}$} & \multicolumn{3}{|c|}{$\begin{array}{c}\text { Class } 4 \\
\text { Low adaptation-stable }\end{array}$} & & & \\
\hline School readiness & .20 & .53 & 1.22 & .43 & 1.16 & 1.54 & .24 & 1.36 & 1.27 \\
\hline Social competence & .12 & .61 & 1.13 & .12 & 1.39 & 1.13 & .001 & 1.65 & 1.00 \\
\hline Play interference & .37 & .30 & .69 & .71 & .67 & 2.03 & 1.08 & .77 & 2.95 \\
\hline Play interruption & .33 & .29 & 1.39 & -.86 & .92 & .42 & -1.19 & 1.05 & .30 \\
\hline
\end{tabular}

${ }^{*} p<.05$.

학교 적응도가 지속적으로 유지되는 형태를 보이는 아동들로 47명(3.71\%)을 차지하며 저적응 유지 집단으로 명명하였다. 각 잠재계층별 발달궤적을 Figure 3에 제시하였으며 초등학교 1-3학년 아동의 학교적응은 각기 다른 4 개의 이질적인 변화궤 적을 가지는 것을 확인할 수 있다.

\section{학교적응의 잠재계층 유형에 영향을 미치는 변인}

연구문제 3인 초등학교 1-3학년 아동의 학교적응 변화궤적에 미치는 유아기 학교준비도, 사회적 유능감, 놀이상호작용, 놀 이방해, 놀이단절의 영향을 알아보기 위해 다항 로지스틱 회 귀분석을 실시했다(Table 7 참조). 실시된 다항 로지스틱 회 귀분석에서 종속변수가 3 개 이상이므로 기준집단(reference group)을 설정 후 승산비(Odds Ratio [OR])를 활용하여 해석하 였다. 승산비의 해석은 1 보다 작을 경우 기준집단에 비해 비교 집단에 포함될 승산이 감소함을 의미하며, 1 보다 큰 경우 기준 집단에 비해 비교집단에 포함할 승산이 증가함을 의미한다(S. Hong, 2005). 또한, 승산비가 1 인 경우 기준집단과 비교집단 간 속할 승산이 동일함을 의미한다.
주요 결과는 다음과 같다. 첫째, 적응 감소 집단을 기준집단 으로 설정하여 고적응 유지 집단과 비교하여 분석한 결과, 학 교준비도가 증가할 때 적응 감소 집단에 비해 고적응 유지 집 단에 속할 가능성(승산)이 2.16배 증가하고, 사회적 유능감이 증가할 때 적응 감소 집단에 비해 고적응 유지 집단에 포함될 가능성(승산)이 4.71배 증가하는 것으로 나타났다. 즉, 적응 감 소 집단과 고적응 유지 집단을 구분해주는 것은 학교준비도 와 사회적 유능감으로, 학교준비도와 사회적 유능감이 증가할 때 고적응 유지 집단에 속할 확률이 증가함을 알 수 있다. 둘 째, 적응 감소 집단을 기준집단으로 설정하여 적응 증가 집단 과 비교하여 분석한 결과, 학교준비도가 증가할 때 적응 감소 집단에 비해 적응 증가 집단에 포함될 가능성(승산)이 2.20배 증가하고, 사회적 유능감이 증가할 때는 적응 감소 집단에 비 해 적응 증가 집단에 포함될 가능성(승산)이 5.33배 증가하는 것으로 나타났다. 이를 통해 적응 감소 집단을 기준집단으로 할 때 적응 감소 집단과 적응 증가 집단을 구분해주는 변인이 학교준비도와 사회적 유능감이며, 학교준비도와 사회적 유능 감이 증가할 때 적응 증가 집단에 속할 확률이 증가함을 알 수 있다. 셋째, 적응 감소 집단을 기준집단으로 설정하여 저적응 
유지 집단과 비교하여 분석한 결과, 놀이방해가 증가할 때 적 응 감소 집단에 비해 저적응 유지 집단에 포함될 가능성(승산) 이 4.05 배 증가하는 것으로 나타났다. 이를 통해 적응 감소 집 단과 저적응 유지 집단을 구분해 주는 요인은 놀이방해이며, 놀이방해가 증가할 때 저적응 유지 집단에 속할 확률이 증가 함을 알 수 있다. 이상의 연구결과는 초등학교 1-3학년 아동의 학교적응 변화궤적에 영향을 미치는 변인으로 학교준비도와 사회적 유능감 및 놀이방해가 유의했음을 보여준다.

\section{Discussion}

본 연구의 목적은 초등학교 1-3학년 아동의 학교적응 발달궤적 유형을 알아보고, 이에 미치는 유아기의 학교준비도와 사회적 유능감, 그리고 또래 놀이 상호작용의 하위요인인 놀이상호작 용, 놀이방해, 놀이단절의 영향력을 검증하는 것이다. 본 연구 에 나타난 결과를 연구문제 중심으로 논의하면 다음과 같다.

첫 번째 연구문제를 통해 초등학교 1학년 3학년 아동 학교 적응의 하위요인별 변화궤적 유형을 고찰하였다. 하위요인별 로 살펴보면, 학교생활적응은 고적응 유지 집단과 적응 증가 집 단의 2 개 집단으로 나타났으며, 학업수행적응은 고적응 유지 집단과 적응 방향 변동 집단의 2 개 집단으로 나타났다. 또한, 또 래적응은 고적응 유지 집단과 적응 방향 변동 집단, 적응 증가 집단의 3 개 집단으로 나타났으며, 교사적응은 고적응 유지 집 단과 적응 증가 집단, 적응 감소 집단의 3 개 집단으로 나타났다.

하위요인별 변화궤적 유형을 보다 자세히 살펴보면 첫째, 학교생활적응의 계층 1 은 고적응 유지 집단(79.41\%)으로 모 든 시점에서 4점을 넘는 높은 수준을 보여주었으며, 계층 2는 적응 증가 집단(20.58\%)으로 학교생활적응 수준이 점차적으 로 증가하는 특성을 가진다. 이러한 연구결과는 초등학생의 학년이 증가할수록 학교생활적응이 높아진다는 선행연구(C. Lee, Shon, \& Jeong, 2016) 결과와 맥락을 같이한다. 초등학교 저학년 아동의 경우 학교생활에 대한 적응에 있어서 대다수의 경우 꾸준하게 높은 수준을 유지하고 있으며, 일부 초반에 다 소 저조한 적응을 보이는 아동이 있더라도 점차 적응 수준이 상승되고 있는 것으로 해석할 수 있다.

둘째, 학업수행적응은 계층 1은 고적응 유지(87.86\%)로 1-3 학년까지 대체로 높은 수준으로 일정하게 학업수행적응을 보 이는 집단이며, 계층 2 는 적응 방향 변동 집단(12.45\%)으로 초 등학교 2학년에 감소하다가 3학년에 다시 증가하는 특성을 가지는 것을 나타났다. 학업수행적응은 의사표현이나 활동의
의욕성, 수업시간의 적극적인 자세를 의미한다(Chi \& Jung, 2006). 저학년 초등학생의 적극적인 학업수행적응은 수업적 응 뿐 아니라, 친구적응, 교사적응, 규칙적응, 환경적응에까지 도 영향을 미친다는 중요성을 보고하고 있다(E.-J. Kim, 2009; K. Lee \& Lee, 2013). 이에 본 연구결과는 학령초기의 학업수행 과 관련된 높은 학교적응이 꾸준히 유지될 수도 있는 반면, 감 소했다가 상승하는 등의 변동을 보일 수도 있음을 시사한다.

셋째, 또래적응에서 계층 1 은 일정한 수준으로 높은 수준을 유지하고 있는 고적응 유지 $77.98 \%$ 가 해당되며, 계층 2는 적 응 방향의 변동을 보이는 집단 $4.81 \%$, 계층 3 은 꾸준히 증가하 는 집단 $17.19 \%$ 가 해당되며, 3집단 모두 3학년에서는 4점 이 상으로 높은 또래적응을 보여주고 있다. 이는 학년이 증가하 면서 친구에 대한 가치가 중요하기 때문에 또래적응이 점차 높아진다고 보고한 선행연구(A.-S. Hong \& Cho, 2014)와 맥락 을 같이한다.

넷째, 교사적응은 세 개의 잠재계층으로 고적응 유지(계층 1), 적응 증가(계층 2), 적응 감소(계층 3) 집단으로 구분되었으 며 적응 감소 집단은 $8.99 \%$ 였지만 학교적응 수준이 점차 증가 하는 아동의 비율은 전체적으로 $91 \%$ 가량으로 매우 높은 것으 로 나타났다. 이와 같은 연구결과는 초등학교 저학년은 교사 의 역할에 따라 학교적응에 많은 영향을 받으며, 교사는 아동 이 학교적응을 돕는 매우 중요한 요인이라고 보고한 선행연구 (E.-J. Kim, 2009)를 지지한다. Lynch와 Cicchetti (1997)는 학생 들이 지각한 교사행동을 통해 교사와의 관계뿐만 아니라 학교 수업, 또래관계, 다양한 학교규칙 등에 대한 가치인식이 생기 며, 정도에 따라 학교적응에 영향을 미친다고 보고하였다. 반 면 교사적응의 경우 완만하게 감소하는 경향을 보이는 집단이 나타났는데 이는 초등학교 저학년 교사는 학생들의 학교생활 을 잘 적응할 수 있도록 민감하게 반응하고 세심한 관찰과 지 도가 필요함을 시사한다. 이상의 연구결과를 통해 초등학교 학교적응 과정은 적응의 하위요인별로 상이한 변화궤적을 보 이는 것을 알 수 있다. 또한, 하위요인별로 상이한 변화양상을 보이는 2-3개의 집단유형을 통해 초등학교에 입학 후 저학년 시기 동안 진급하면서 학교적응의 정도가 다양한 궤적으로 변 화할 수 있음을 알 수 있다. 학교적응에서의 가장 큰 인적요인 인 교사와 부모가 이에 대해 인지하고 각 유형에 적합한 지원 과 지도를 제공하는 것이 요구됨을 시사한다.

두 번째 연구문제에서 초등학교 1-3학년 아동의 학교적응 변화궤적은 어떠한 유형으로 구분되는지 검증한 결과, 초등 학교 1-3학년의 학교적응 변화유형은 4 개 잠재계층으로 유 형화하는 것이 적절한 것으로 나타났다. 4 개 잠재계층의 변 
화 특성을 반영한 집단명과 전체에서 차지하는 비율은 적응 감소 집단(16.56\%), 고적응 유지 집단(65.69\%), 적응 증가 집 단(14.04\%), 저적응 유지 집단(3.71\%)이다. 본 연구결과는 학 교적응이 시간적 추이에 따라 변화하는 속성을 지니고 있다 는 측면과 함께 동일한 학년이라도 학교적응 변화궤적이 상이 하다는 선행연구(Jeon et al., 2020; Nam \& Kim, 2017) 결과를 지지한다. 본 연구와 같이 초등학교 1-3학년의 학교적응 발 달궤적을 고찰한 Jeon 등 (2020) 또한 감소, 고수준유지, 증가, 저수준유지의 4 개 잠재계층으로 보고하고 있다. Nam과 $\mathrm{Kim}$ (2017)은 초등학교 4학년에서 중학교 2학년까지의 아동들의 학교적응 발달궤적을 고찰한 결과 다섯 개의 유형(점진적 적 응감소군, 점진적 적응 증가군, 고적응 유지군, 저적응 유지군, 점진적 미세 감소군)으로 구분하여 제시한 바 있다. 이와 같은 결과들을 종합할 때 초등학교 저학년의 학교적응은 다양한 양 상의 변화궤적을 보이며, 변화되는 양상은 고학년과 중학교까 지 이어지는 것으로 결론지을 수 있다.

본 연구결과를 통해 도출된 네 개의 잠재계층을 토대로 변 화 유형에 대해 구체적으로 살펴보면 첫째, 적응 감소 집단은 초기에는 적응 증가 집단보다 높은 학교적응을 보였으나, 학 년 증가에 따라 학교적응이 감소하는 경향을 보였다. 둘째, 고 적응 유지 집단은 가장 많은 아동비율을 차지했는데, 1 학년 3 학년까지 대체로 일정하게 높은 수준으로 학교적응을 하는 것으로 나타났다. 이러한 연구결과는 초등학교 입학 후 학교 생활에 잘 적응하는 아동은 초등학교에 대해 긍정적인 태도 를 형성하게 되어 원만한 대인관계를 형성하고 높은 학업성취 를 나타내게 되며, 이를 통하여 꾸준히 학교적응을 잘 하는 것 으로 보고한 선행연구(Yi \& Jun, 2019) 결과와 맥락을 같이한 다. 또한, 초등학교에서의 학교적응 수준이 이후 중학교 시기 의 적응을 예측하는 것으로 보고한 선행연구(Chung, 2003) 결 과 및 초등학교 적응이 아동의 인지와 사회.정서적 발달뿐만 아니라 학교에 대한 긍정적 인식 형성에도 관련된다는 선행연 구(Jason \& Glenwick, 1993) 결과를 지지한다. 셋째, 적응 증가 집단은 시간의 경과에 따라 학교적응이 증가하는 특성을 보였 다. 또한, 적응 증가 집단에 속한 아동들은 초등학교 3학년이 되면서 적응에 전혀 어려움이 없던 고적응 유지 집단과 거의 비슷한 수준으로 학교적응이 높게 나타났다. 넷째, 저적응 유 지 집단은 각 측정 시점 모두에서 다른 집단들에 비하여 낮은 학교적응을 보였으며, 시간의 추이에도 불구하고 지속적으로 낮은 학교적응을 유지하는 양상을 보였다. 이러한 연구결과는 학교와 가정에서 학교적응 증가 집단과 관련된 긍정적 영향요 인에 대해 탐색할 필요가 있음을 제안한다. 또한, 학교적응 감
소 집단과 저적응 유지 집단에 미치는 부정적 요인을 규명하 여 초등학교 저학년 아동에게 미치는 문제행동을 예방하고 학 교적응에 도움을 줄 수 있음을 시사한다. 따라서 초등학교 교 사가 저학년 학생의 학교적응을 돕기 위해 다양한 양상을 보 이는 집단특성에 적합한 차별화된 지원을 통해 개별적으로 도 움을 주는 것이 요구된다.

세 번째 연구문제를 통해 초등학교 1 학년 3 학년 아동의 학교적응 변화궤적을 예측하는 변인(학교준비도, 사회적 유 능감, 놀이상호작용, 놀이방해, 놀이단절)의 영향력을 검증한 결과, 놀이상호작용과 놀이단절을 제외한 변인들이 유의한 영 향을 미치는 것으로 나타났다. 구체적으로 살펴보면 첫째, 유 아기의 학교준비도가 높을수록 적응 감소 집단보다는 고적응 유지 집단과 적응 증가 집단에 속할 확률이 높게 나타났다. 이 는 학교적응의 높은 초기값을 가지고 있는 학교준비도가 높은 아동일수록 학교적응이 높은 집단에 속할 가능성이 크다는 것 을 의미한다. 본 연구결과는 유아의 취학 전 학교준비도가 초 등학교 아동의 학교적응에 긍정적인 영향을 미침을 밝힌 선행 연구(An, 2014)의 결과와 맥락을 같이하는 것이다.

둘째, 유아기의 사회적 유능감이 높을수록 적응 감소 집단 보다는 고적응 유지 집단과 적응 증가 집단에 속할 확률이 높 은 것으로 나타났다. 이는 높은 사회적 유능감을 보이는 아동 일수록 높은 학교적응을 유지할 가능성이 높음을 의미하며, 아동의 성공적인 초등학교 적응을 위하여 사회적 유능감을 높 여주고 지원할 필요가 있음을 시사한다. 본 연구결과는 아동 의 사회적 유능감이 초등학교 적응에 긍정적으로 영향을 미 친다고 보고한 선행연구(Kang \& Lee, 2001; K.-H. Lee, 2018; S. Lee \& Oh, 2019; S. A. Lee \& Lim, 2019)와 맥락을 같이한다. 셋 째, 유아의 놀이방해가 높을수록 적응 감소 집단보다는 저적 응 유지 집단에 속할 확률이 높았다. 저적응 유지 집단은 학교 적응의 초기값이 가장 낮은 집단으로 놀이방해가 높을수록 초 기에 학교적응이 낮은 집단에 속할 가능성이 높음을 의미한 다. 본 연구결과는 유아기에 나타나는 또래 놀이 상호작용에 서의 놀이방해 정도가 초등학교에 진학 후 학교적응에 부정적 으로 영향을 미친다는 선행연구(E. J. Choi \& Kim, 2020; Jung $\& \mathrm{Chi}, 2006)$ 결과와 맥락을 같이한다.

본 연구는 성장혼합모형을 통해 초등학교 1학년 3 학년의 학교적응 발달 양상에 따른 이질적 계층이 존재함을 밝히고, 이와 같은 학교적응 발달궤적과 관련된 변인으로 학교준비도 와 사회적 유능감 및 놀이방해의 영향력을 검증하였다. 즉, 시 간의 흐름에 따라 학교적응의 하위요인별 변화궤적이 상이함 을 밝혔으며, 총체적인 학교적응과 관련하여 각 잠재계층에 
미치는 학교준비도와 사회적 유능감 및 또래 놀이 상호작용의 영향력을 검증했다. 본 연구결과는 학교적응의 잠재유형별 개 인의 생애주기에 맞춘 차별화된 학교적응 프로그램의 계발이 요구되며, 초등학교 저학년 아동의 원활한 학교적응을 지원하 기 위한 체계적이고 다양한 방안이 모색되어야 함을 시사한 다. 나아가 본 연구결과는 초등학교의 교사가 아동의 다양한 개인적, 가정적 특성을 이해하고 이에 부합되는 학교적응 프 로그램을 제공한다면 학교적응의 변화궤적을 변화시킬 수 있 음을 암시한다. 이와 함께, 학교적응에 대한 유아기의 학교준 비도와 사회적 유능감 및 놀이방해의 유의한 영향력은 유아교 육기관과 초등학교가 상호 협력하여 학교적응을 지원하는 프 로그램을 계발할 필요가 있음을 시사한다.

본 연구가 가진 제한점과 추후 연구를 위한 제언을 기술하 면 다음과 같다. 먼저 본 연구에서 사용된 제변인들은 패널연 구에서 담임교사의 설문보고만을 통해 조사된 자료이다. 후속 연구에서 아동을 대상으로 직접 설문이나 면접을 통해 자료를 수집할 수 있겠으며, 심층면담이나 관찰과 같은 질적인 자료 수집을 통해 추가적으로 변인 간의 구조 및 관계성을 고찰할 수 있을 것이다. 본 연구는 패널 자료를 사용하여 전국 단위의 대표성 있는 연구대상을 통해 자료를 수집했다는 장점을 가 지는 반면, 패널 자료에서 기선정한 변인과 측정도구를 활용 한 자료를 제한적으로 활용했다는 한계점을 가진다. 이에 통 해 초등학생의 학교적응 잠재계층 유형과 관련된 다양한 변인 을 지속적으로 탐색할 필요가 있음을 제안한다. 이와 같은 제 한점에도 불구하고 본 연구는 전국 표집의 종단적인 자료와 연구분석 방법을 활용하여 초등학교 저학년 아동의 학교적응 변화양상을 고찰하고, 이와 관련된 유아기 변인들의 영향력을 검증했다는데 그 의의가 있다.

\section{Notes}

This article was presented at the 11th Conference of the Panel Study on Korean Children, winning the 1st prize.

\section{Conflict of Interest}

No potential conflict of interest relevant to this article was reported.

\section{References}

\section{In English}

Coolahan, K., Fantuzzo, J., Mendez, J., \& McDermott, P. (2000). Preschool peer interactions and readiness to learn: Relationships between classroom peer play and learning behaviors and conduct. Journal of Educational Psychology, 92(3), 458-465. doi:10.1037/0022-0663.92.3.458

Fantuzzo, J., Coolahan, K., Mendez, J., McDermott, P., \& SuttonSmith, B. (1998). Contextually-relevant validation of peer play constructs with African American head start children: Penn Interactive Play Scale. Early Childhood Research Quarterly, 13(3), 411-432. doi:10.1016/S0885-2006 (99) 80048-9

Gresham, F. M., \& Elliott, S. N. (1990). Social skills rating system manual. Circle Pines, MN: American Guidance Service.

Hedeker, D. (2004). An introduction to growth modeling. In D. Kaplan (Ed.), The sage handbook of quantitative methodology for the social sciences (pp. 215-234). Thousand Oaks, CA: Sage Publications.

Hill, A. L., Degnan, K. A., Calkins, S. D., \& Keane, S. P. (2006). Profiles of externalizing behavior problems for boys and girls across preschool: The roles of emotion regulation and inattention. Developmental Psychology, 42(5), 913-928. doi:10.1037/0012-1649.42.5.913

Jason, L. A., \& Glenwick, D. S. (1993). Promoting health and mental health in children, youth and families. New York: Springer.

Ladd, G. W. (2005). Children's peer relations and social competence: A century of progress. New Haven, CT: Yale University Press.

Ladd, G. W., Kochenderfer, B. J., \& Coleman, C. C. (1996). Friendship quality as a predictor of young children's early school adjustment. Child Development, 67(3), 1103-1118. doi:10.2307/1131882

Lo, Y., Mendell, N. R., \& Rubin, D. B. (2001). Testing the number of components in a normal mixture. Biometrika, 88(3), 767-778. doi:10.1093/biomet/88.3.767

Lynch, M., \& Cicchetti, D. (1997). Children's relationships with adults and peers: An examination of elementary and junior high school students. Journal of School Psychology, 35(1), 81-99. doi:10.1016/S0022-4405(96)00031-3

Mplus (Version 7.4). [Computer software]. Los Angeles, CA: Muthén \& Muthén.

Murphey, D. A., \& Burns, C. E. (2002). Development of a comprehensive community assessment of school readiness. Early Childhood Research and Practice, 4(2), 1-12. Retrieved from ERIC database. (ED471906)

Muthén, B. (2004). Latent variable analysis: Growth mixture 
modeling and related techniques for longitudinal data. In D. Kaplan (Ed.), Handbook of quantitative methodology for the social sciences (pp. 345-368). Newbury Park, CA: Sage.

Ramey, C. T., \& Ramey, S. L. (2004). Early learning and school readiness: Can early intervention make a difference? Merrill-Palmer Quarterly, 50(4), 471-491. doi:10.1353/ mpq.2004.0034

Raver, C. C., \& Zigler, E. F. (1997). Social competence: An untapped dimension in evaluating head start's success. Early Childhood Research Quarterly, 12(4), 363-385. doi:10.1016/ S0885-2006(97)90017-X

Richman, J. M., Bowen, G. L., \& Woolley, M. E. (2004). School failure: An eco-interactional development perspective. In M. W. Fraser (Ed.), Risk and resilience in childhood: An ecological perspective (pp. 133-160). Washington, DC: NASW Press.

Rouse, H. L., \& Fantuzzo, J. W. (2009). Multiple risks and educational well being: A population-based investigation of threats to early school success. Early Childhood Research Quarterly, 24(1), 1-14. doi:10.1016/j.ecresq.2008.12.001

United States., National Education Goals Panel., \& Goal 1 Technical Planning Group. (1995). Reconsidering children's early development and learning: Toward common views and vocabulary. Washington, DC: National Education Goals Panel.

Wickrama, K. A. S., Lee, T. K., O’Neal, C. W., \& Lorenz, F. O. (2016). Higher-order growth curves and mixture modeling with Mplus: A practical guide. New York and London: Routledge.

\section{In Korean}

An, Y.-H. (2014). Impact of elementary school adjustment program for five-year-olds on school readiness. Korea Journal of Child Care and Education, 87, 51-82.

Chi, S.-A., \& Jung, D.-H. (2006). Validation of school adjustment inventory for first grade elementary school students. Korean Journal of Child Studies, 27(1), 1-15.

Choi, E. J., \& Kim, K. J. (2020). The effect of child's peerplay interaction characteristics on self-esteem and school adjustment at first grade of elementary school. Journal of Future Early Childhood Education, 27(2), 215-234. doi:10.22155/JFECE.27.2.215.234

Choi, H. Y., \& Shin, H. Y. (2008). Validation of the Penn Interactive Play Scale for Korean children. Korean Journal of Child Studies, 29(3), 303-318.

Choi, S., \& Yoo, M. S. (2019). The concurrent and lagged effects of parental neglect and abuse on longitudinal changes in late childhood school adjustment. The Korean Journal of School Psychology, 16(1), 1-15. doi:10.16983/kjsp.2019. 16.1.1
Chung, H. (2003). Predictors of psychological maladjustment following middle school transition. The Korea Journal of Youth Counseling, 11(2), 36-46.

Her, E. H., \& Kim, S. L. (2020). The effect of teacher-child interaction on young children's school readiness of children in transition period of elementary school: Mediating effects of academic ability and social competence. Korean Journal of Child Education and Care, 20(1), 1-16. doi:10.21213/ kjcec.2020.20.1.1

Hong, A.-S., \& Cho, G.-P. (2014). The effect of social support, academic self-efficacy and school life adjustment of elementary school students on their school happiness and academic achievement. Journal of Learner-Centered Curriculum and Instruction, 14(1), 45-68.

Hong, S. (2000). The criteria for selecting appropriate fit indices in structural equation modeling and their rationales. Korean Journal of Clinical Psychology, 19(1), 161-177.

Hong, S. (2005). Ihang mich dahang lojiseutig [이항 및 다항 로지 스틱 회귀분석]. Seoul: Gyoyugmunhwasa.

Hong, Y.-J., An, H.-R., Lee, K., \& Choi, N. (2018). Peer play discontinuity and school readiness in 5-year-olds: The moderating effect of social competence. The Korean Journal of the Human Development, 25(3), 133-152. doi:10.15284/ kjhd.2018.25.3.133

Jeon, H., Kim, S., \& Hong, S. (2020). Trajectories in lower grade elementary school students' school adjustment and their determinants: Using growth mixture models. Survey Research, 21(3), 113-140. doi:10.20997/SR.21.3.5

Jung, D.-H., \& Chi, S.-A. (2006). A study of the relationships among children's peer interactions, child-teacher relationships, multiple intelligences, and elementary school adjustment. Korean Journal of Early Childhood Education, 26(3), 201-221.

Kang, S. R., \& Lee, K. N. (2001). The relation of peer victimization and social competence to children's school adjustment. Dong-a Education Review, 27, 161-179.

Kim, E.-J. (2009). Effects of the elements of cognitive $\&$ affective learning style on the adjustment to elementary school of low-grade students. The Journal of Elementary Education, 22(1), 439-457.

Kim, H. S. (2013). A study on development of young children's learning attitude scale for teachers. Korean Journal of Child Education and Care, 13(3), 1-17.

Kim, J. (2019). An analysis of exploring the effects of school readiness on school adjustment and academic achievement. Journal of Learner-Centered Curriculum and Instruction, 19(8), 1111-1130. doi:10.22251/jlcci.2019.19.8.1111

Lee, C., Shon, K., \& Jeong, E. (2016). The relation between first grade students' adoption and class participation: The moderating effects of perceived teachers' control. Journal of Learner-Centered Curriculum and Instruction, 16(2), 45-73. 
Lee, E., Lee, S., \& Hong, S. (2016). The effects of community child-center service on school adjustment change trajectory: Using second-order latent growth model. Korean Journal of Social Welfare Research, 50, 59-85. doi:10.17997/SWRY. 50.1 .3

Lee, J., Kang, S., Lee, K., \& Yi, S. (2015). The effects of parenting practice on the trajectories of change in the school adjustment of upper elementary students. Korean Journal of Child Studies, 36(4), 91-110. doi:10.5723/KJCS.2015.36.4.91

Lee, K., \& Lee, M. (2013). Effects of personal, family, and school variables on school adjustment among elementary school and middle school students. Journal of Life-span Studies, 3(1), 13-28.

Lee, K.-H. (2018). A longitudinal study among early childhood variables influencing school adjustment. The Journal of Korea Open Association for Early Childhood Education, 23(6), 399-425. doi:10.20437/KOAECE23-6-17

Lee, S. A., \& Lim, S. A. (2019). The mediated effects of school readiness and social skills in the relationship between children's developmental characteristics and first graders' school adjustment. The Journal of Korea Elementary Education, 30(1), 221-233. doi:10.20972/Kjee.30.1.201903.221

Lee, S., \& Oh, S. (2019). The effect of media utilization in early childhood on the adaptation of elementary school: Social competence mediated effects. Korean Journal of Children's Media, 18(2), 89-108. doi:10.21183/kjcm.2019.6.18.2.89

Lee, Y., \& Chung, H. (2016). A longitudinal study of developmental trajectories and predictors of school adjustment in early adolescence. Studies on Korean Youth, 27(2), 187-214. doi:10.14816/sky.2016.27.2.187

Nam, J.-Y., \& Kim, J. C. (2017). The relationship between the types of absence of parents after school and latent class of school adjustment change. Korean Journal of Youth Studies, 24(6), 281-306. doi:10.21509/KJYS.2017.06.24.6.281

Oh, S., \& Lee, S. (2019). Effects of childhood development on the application of primary school 1 st grade by gender. The
Journal of Child Education, 28(3), 135-149. doi:10.17643/ KJCE.2019.28.3.07

Panel Study on Korean Children. (2018). Panel study of Korean children 7-10th survey [Data file and codebook]. Retrieved from https://panel.kicce.re.kr/panel/module/rawDataManage/index. do

Park, W. Y., Ma, J. S., \& Chon, E. Y. (2004). A study on the young children's playfuless and interactive peer play. The Journal of Korea Open Association for Early Childhood Education, 9(4), 285-298.

Suh, M.-O. (2004). A validation of the Korean version of the Social Skill Rating System for preschool level (K-SSRS: Teacher and parent forms). Korean Journal of Early Childhood Education, 24(2), 223-242.

Yeom, M., \& Moon, H. (2008). A longitudinal study on the effects of the transition from early childhood schooling to elementary school. Korean Journal of Early Childhood Education, 28(6), 91-118.

Yi, Y., \& Jun, E. (2019). Exploring variables affecting school adjustment in first grade elementary students: Focused on mother's employment, home environment, and children's executive function difficulty. Korean Journal of Child Care and Education Policy, 13(1), 101-121. doi:10.5718/kcep. 2019.13.1.101

\section{ORCID}

Eun Ha Her

Sang Lim Kim http://orcid.org/0000-0002-4446-5139

http://orcid.org/0000-0002-9524-263X
Received October 31, 2020

Revision received December 03, 2020

Accepted December 08, 2020 